\title{
THE
}

\section{Evaluating how variants of floristic quality assessment indicate wetland condition}

\author{
Thomas E. Kutcher \\ Graham E. Forrester \\ University of Rhode Island, gforrester@uri.edu
}

Follow this and additional works at: https://digitalcommons.uri.edu/nrs_facpubs

The University of Rhode Island Faculty have made this article openly available.

Please let us know how Open Access to this research benefits you.

This is a pre-publication author manuscript of the final, published article.

Terms of Use

This article is made available under the terms and conditions applicable towards Open Access Policy Articles, as set forth in our Terms of Use.

\section{Citation/Publisher Attribution}

Kutcher, T.E., Forrester, G. E.Evaluating how variants of floristic quality assessment indicate wetland condition (2018) Journal of Environmental Management 217:231-239 https://doi.org/10.1016/ j.jenvman.2018.03.093

This Article is brought to you for free and open access by the Natural Resources Science at DigitalCommons@URI. It has been accepted for inclusion in Natural Resources Science Faculty Publications by an authorized administrator of DigitalCommons@URI. For more information, please contact digitalcommons-group@uri.edu. 


\title{
The ecological mechanisms driving floristic quality assessment of wetland integrity
}

\author{
Thomas E. Kutcher ${ }^{1 *}$ and Graham E. Forrester ${ }^{2}$
}

4

${ }^{1}$ Rhode Island Natural History Survey, University of Rhode Island, Kingston, RI, 02881

${ }^{2}$ Department of Natural Resources Science, University of Rhode Island, Kingston, RI, 02881

\section{Highlights}

- Understanding response is critical to bioindicator utility.

- Plant conservatism responds predictably to specific and aggregate disturbance.

- Plant species richness confounds predictable response of conservatism in FQA.

- Non-native species are important for assessing wetland integrity with FQA.

* Corresponding author Email: tkutcher@rinhs.org

Postal Address: PO Box 1858, Kingston, RI, 02881 


\section{Abstract}

27 Biological indicators are useful tools for the assessment of ecosystem condition. Multi-metric

28 and multi-taxa indicators may respond to a broader range of disturbances than simpler indicators, but their complexity can make them difficult to interpret, which is critical to indicator utility for ecosystem management. Floristic Quality Assessment (FQA) is an example of a biological assessment approach that has been widely tested for indicating freshwater wetland condition, but less attention has been given to clarifying the mechanisms controlling its response. FQA indices quantify the aggregate of vascular plant species tolerance to habitat degradation (conservatism), and variants have incorporated species richness, abundance, and indigenity (native or nonnative). To assess bias, we tested FQA variants in open-canopy freshwater wetlands against three independent reference measures, using practical vegetation sampling methods. FQA variants incorporating species richness did not correlate with our reference measures and were influenced by wetland size and hydrogeomorphic class. In contrast, FQA variants lacking measures of species richness responded linearly to reference measures quantifying individual and aggregate stresses, suggesting a broad response to cumulative degradation. FQA variants incorporating non-native species improved performance over using only native species, and incorporating relative species abundance did not improve performance further. We relate our empirical findings to ecological theory to clarify the mechanisms and functional implications of the FQA variants. Our analysis indicates that (1) aggregate conservatism declines with increased disturbance; (2) species richness has varying relationships with disturbance and increases with site area, confounding FQA response; (3) non-native species are favored by human disturbance; and (4) proportional abundance of species provides important functional information at the site level. Using our practical sampling methods, an FQA variant ignoring species richness and incorporating non-native species and relative species abundance can be logistically efficient, easily understood, and effective for wetland assessment.

\section{Keywords}

Biological indicator; ecological integrity; non-native species; species richness; vascular plant; wetland assessment 


\section{Introduction}

Biological indicators (or bioindicators) are widely used to indicate environmental condition (U.S. EPA, 2006). Effective bioindicators act as continuous, integrative in-situ ecosystem monitors that react predictably to multiple, cumulative, or synergistic environmental factors, and detect episodic events that periodic physical or chemical monitoring may not capture (Barbour et al., 1996). Bioindicators range in complexity from single indicator species to multimetric indices based on multiple attributes of multiple taxa. Multi-metric and multi-taxa indicators are attractive to practitioners interested in assessing ecological integrity because they theoretically integrate a more diverse response to environmental conditions than simpler indicators (Birk et al., 2012; Karr, 1991), but the complexity of these indicators requires additional time and taxonomic expertise over simpler measures, and may be a drawback if the component metrics show interactive or countervailing responses that make the final indicator difficult to interpret (Karr and Chu, 1999). Interpretability of response is often overlooked (Birk et al., 2012; Niemi and McDonald, 2004) but is central to indicator utility and relies on a clear understanding of the underlying ecological mechanisms (Dale and Beyeler, 2001; U.S. EPA, 2002).

Floristic Quality Assessment (FQA) is an example of a biological assessment approach that has been widely tested, yet remains subject to misuse because the underlying mechanisms driving its functionality have not been fully clarified. FQA is a relatively simple bioindicator, using one to three attributes of vascular flora viewed as a single taxonomic group, yet it has shown potential to integrate and reflect broad aspects of freshwater wetland condition (DeBerry et al., 2015). Like several other bioindicators, FQA relies on ranking species' response to human disturbance. Early bioindicators in aquatic systems used coefficients to characterize species' response to specific stressors, for example rankings of tolerance to organic pollutants (e.g. Hilsenhoff, 1981). FQA, instead, uses "coefficients of conservatism" (CC) that rank the tolerance of plant species to rapid habitat change caused by human disturbance. In the United States, region-specific CC are typically assigned through consensus of a panel of expert botanists. High $\mathrm{CC}$ are assigned to plants with narrow environmental tolerances and high sensitivity to recent human disturbance. Low CC are assigned to disturbance-insensitive species with broad tolerances, and the prevalence of species with high versus low CC is assumed to reflect ecological condition. Although FQA was originally developed to use existing plant inventory data to indicate sites' conservation value (Swink and Wilhelm, 1979), targeted vegetation sampling for FQA is increasingly used to assess freshwater wetland integrity and restoration success (Bried et al., 2013; Cohen et el., 2004; Freyman et al., 2016; Lopez and Fennessey, 2002; Matthews et al., 2009; Matthews et al., 2015; Miller and Wardrop, 2006).

FQA is typically used to indicate broad wetland integrity rather than any single stressor, operating under the general assumptions that aggregate plant conservatism (i.e., sensitivity to human disturbances) responds monotonically to the cumulative effects of a range of human disturbances (U.S. EPA, 2002), and that this response signal is not compromised by inherent variation in other factors such as wetland size, basin morphology, and hydrology (Bried et al., 2013). The original FQA Index (FQAI) uses only native species and incorporates species richness as well as conservatism (Swink and Wilhelm, 1979; Table 1). Like other bioindicators that incorporate species richness, it relies on the assumption that native species richness declines with increasing environmental degradation. The FQAI attracted the interest of freshwater wetland managers because plant species composition is a key functional component of vegetated 
wetlands (Mitsch and Gosselink, 2000). Additionally, combining measures of tolerance and diversity is intuitively meaningful, and FQAI can be applied using basic plant inventory methods (Bourdaghs et al., 2006; Lopez and Fennessey, 2002).

As it has been tested and applied, however, researchers have suggested that different components and variants of the original FQAI formula may better predict wetland integrity. Each of these variants alters the underlying implicit assumptions of the index. Rooney and Rogers (2002) discount the assumption that native species richness declines with increasing environmental degradation, and suggest that Mean $C C_{n}$ alone may better reflect ecological condition and be easier to interpret. A Mean $C C$ variant including non-native species (Mean $C C_{s}$, where $s$ indicates total species) assumes non-native species are relevant to environmental condition. A variant weighting Mean $C C_{n}$ by species abundance (Weighted mean $C C_{n}$ ), and a weighted variant incorporating non-native species (Weighted mean $C C_{s}$ ) both assume that intolerant species decline in abundance disproportionately with increasing environmental degradation (Bourdaghs et al., 2006; Bried et al., 2013; Chamberlain and Brooks, 2016; Cohen et al., 2004). In these variants, non-native species are typically assigned a $\mathrm{CC}$ of 0 , regardless of their actual conservatism, which assumes they are uniformly insensitive to human disturbance and broadly tolerant. Miller and Wardrop (2006) argued on empirical grounds for a variant that discounts species richness and incorporates non-native species (FQAI'), whereas Matthews et al. (2009) proposed a version of the original FQAI incorporating both non-native species and richness $\left(F Q A I_{s}\right)$. Finally, Ervin et al. (2006) found that simply \% Native, discounting both richness and conservatism, outperformed FQAI.

As FQA gains recognition as an indicator of freshwater wetland condition, there is a growing need to clarify the implications of selecting particular FQA variants (e.g., Bourdaghs, 2012; Mirazadi et al., 2017). While the utility of several variants of the original FQA metric has been empirically evaluated, less attention has been given to comparing their ecological and functional interpretation, leading to disagreement among researchers over the best choice of indicator. In this paper, we empirically test several FQA variants from the literature against three tested, independently-derived (1) landscape, (2) rapid, and (3) biological measures (hereafter, reference measures). By using three separate reference measures representing (1) indirect aggregate stress, (2) direct individual and cumulative stress, and (3) biological response, we assess the robustness of empirical evaluation to bias in any one reference measure. Because some metric components, particularly species richness, are sensitive to sampling effort (DeBerry et al. 2015), we apply data-collection methods designed to be practical and effective for state and tribal assessment protocols and analyze how the FQA variants respond to reduced sampling. Most importantly, we use relevant ecological theory to interpret our empirical findings and clarify the functional mechanisms of the FQA variants, which may help practitioners to better plan and interpret assessments and manage wetland resources.

\section{Methods}

\subsection{Study sample}

Our study was conducted in Rhode Island (RI), USA. Our study sample comprised 20 freshwater wetland sites that had been previously assessed using landscape, rapid, and biological assessment measures (Kutcher and Bried, 2014), which were also applied as reference measures in this study. The sites were selected evenly across rapid assessment index scores from a larger set of wetlands $(n=51)$ to represent a broad range of undisturbed through highly-disturbed 
conditions. The sites were spread geographically across Rhode Island. The site boundaries were delineated by basin continuity, bound by any combination of upland, riverine open water, or lacustrine open water, large roads or railways lacking culverts, or changes in hydrogeomorphology. We selected open-canopy vegetated wetlands (tree cover $<50 \%$ ) with substantial emergent vegetation (> $25 \%$ cover), but sites were not divided by vegetation type, thus a single site could contain multiple vegetation community types. Sites ranged in size from 0.12 to 12 hectares with a mean of 2.5 hectares and fell into three hydrogeomorphic classes (modified from Brinson (1993)): isolated depression $(n=10)$, connected depression $(n=5)$, and floodplain riverine $(n=5)$. The most commonly represented vegetation classes (per Cowardin et al., 1979) were emergent (in 20 sites), scrub-shrub (in 15 sites), and forested (in 12 sites) wetlands.

\subsection{Vegetation sampling for $F Q A$}

To address the assumptions of FQA methodology, while considering metric operability and user practicality, our vegetation sampling aimed to efficiently produce a nearly-complete list of vascular plant species per site and estimate the coarse relative cover of each species. Vegetation data were collected along three 4-m wide belt transects, the first running entirely across the longest dimension of the site, and the remaining two running entirely across the site perpendicular to the first at one-third and two-thirds the distance from the start of the first transect. For riverine wetlands that were sinuous and narrow, the first transect was composed of the fewest connected straight lines needed to approximately follow the contours of the site. Transects were hand-drawn on aerial photographs prior to site visits, and landmarks visible on the maps (such as evergreen trees, rocks, roads) were used to navigate in the field. The data were collected during a single site visit at the peak of the growing season (mid-July through September). Every vascular plant observed was identified to species and recorded onto field datasheets. Plants that could not be identified in the field were tagged and placed in plastic bags for laboratory identification. The few immature samples that could not be identified in the field or laboratory were not included in our analysis.

Following the survey of each transect, an abundance rank of each species was estimated as follows: rank $1=$ scarce $(<10 \%$ cover $)$, rank $2=$ common $(10-60 \%$ cover $)$, and rank $3=$ dominant (> 60\% cover). Site-wide mean ranks were used as replicates for data analysis. Incidental observations of species observed outside of the transects were added to species totals and assigned a site-wide abundance rank of 1 . We chose broad, easily-estimated cover classes to capture key functional aspects of species relative groundcover dominance (e.g., habitat value, productivity), while minimizing the labor-intensive logistics that may hinder more rigorous cover class estimation methods (Bourdaghs et al. 2006).

\subsection{Generating FQA indices}

We tested FQA index variants and components taken directly from prior studies, or developed based on a logical extension of published, empirically-tested formulas (Table 1). Values for each FQA index were calculated for each of our 20 study sites using recent Rhode Island-specific plant CC. The CC were assigned, by R. Enser (unpublished data), to all vascular plant species known to exist in Rhode Island, according to methods detailed in Bried et al. (2012). The CC were based mainly on each species' relative sensitivity to human disturbances and, to a lesser degree, on niche width (R. Enser, personal communication). Non-native species (not native to Rhode Island) were assigned a CC of zero. In total, 1558 species were assigned 
CC; values ranged from 0 to 10 with a mean of $3.7 \pm 2.9$ and a median of 3 ; non-native species comprised $28 \%$ of these species. For the FQA indices that use species abundance, calculations were made using midpoints of cover class ranges, where Rank $1=5 \%$ cover, Rank $2=35 \%$ cover, and Rank $3=80 \%$ cover.

Table 1. Variants and components of the FQAI formula and exemplary applications in freshwater wetland assessment

\begin{tabular}{|c|c|c|c|}
\hline $\begin{array}{l}\text { FQA Variant } \\
\text { or Component }\end{array}$ & ${ }^{\mathrm{a} F o r m u l a}$ & Recent Applications & $\begin{array}{l}\text { Equivalent } \\
\text { Formula }\end{array}$ \\
\hline$F Q A I$ & $\frac{\sum_{i=1}^{N} C C_{i}}{N} \times \sqrt{N}$ & Lopez and Fennessy, 2002 & \\
\hline$F Q A I_{s}$ & $\frac{\sum_{i=1}^{S} C C_{i}}{S} \times \sqrt{S}$ & $\begin{array}{l}\text { Bourdaghs et al., 2006; } \\
\text { Matthews et al., } 2009\end{array}$ & \\
\hline Mean $C C_{n}$ & $\frac{\sum_{i=1}^{N} C C_{i}}{N}$ & $\begin{array}{l}\text { Bourdaghs et al., 2006; } \\
\text { Cohen et al., 2004; Miller } \\
\text { and Wardrop, 2006; Rooney } \\
\text { and Rogers, } 2002\end{array}$ & \\
\hline Mean $C C_{s}$ & $\frac{\sum_{i=1}^{S} C C_{i}}{S}$ & $\begin{array}{l}\text { Bourdaghs et al., 2006; } \\
\text { Chamberlain and Brooks, } \\
\text { 2016; Cohen et al., 2004; } \\
\text { Matthews et al., } 2009\end{array}$ & Mean $C C_{n} \times \frac{N}{S}$ \\
\hline $\begin{array}{l}{ }^{\mathrm{b}} \text { Weighted } \\
\text { Mean } C C_{n}\end{array}$ & $\frac{\sum_{i=1}^{N}\left(C C_{i} \times P_{N}\right)}{\sum_{i=1}^{N} P_{N}}$ & $\begin{array}{l}\text { Cohen et al., 2004; } \\
\text { Bourdaghs et al., } 2006\end{array}$ & \\
\hline $\begin{array}{l}\text { Weighted } \\
\text { Mean } C C_{s}\end{array}$ & $\frac{\sum_{i=1}^{S}\left(C C_{i} \times P_{S}\right)}{\sum_{i=1}^{S} P_{S}}$ & $\begin{array}{l}\text { Bell et al., 2017; Bourdaghs } \\
\text { et al., } 2006\end{array}$ & \\
\hline${ }^{\mathrm{c}} F Q A I^{\prime}$ & $\frac{\sum_{i=1}^{N} C C_{i}}{N \times 10} \times \frac{\sqrt{N}}{\sqrt{S}} \times 100$ & $\begin{array}{l}\text { Chamberlain and Brooks, } \\
\text { 2016; Miller and Wardrop, } \\
2006\end{array}$ & Mean $C C_{n} \times \sqrt{\frac{N}{S}} \times 10$ \\
\hline$\%$ Native & $\frac{N}{S}$ & Ervin et al., 2006 & \\
\hline
\end{tabular}

${ }^{\mathrm{a}} C C=$ plant species coefficient of conservatism; $N=$ number of native plant species recorded; $S=$ total number of plant species recorded (including non-natives); $P_{N}=$ proportional cover of native plant species recorded and $P_{S}=$ 
present $F Q A I$ ' as ' $F Q A I$ relative to maximum-attainable $F Q A I$ ', but this is algebraically equivalent to the product of Mean $C C_{n}$ and the square root of the proportion of native species $(\times 10$, which in relative terms is irrelevant). Similarly, because the assigned CC for any non-native species is typically zero (0), Mean $C C_{s}$ is equivalent to the product of Mean $C C_{n}$ and the proportion of native species (\% Native). Functionally, FQAI' only differs from Mean $C C_{s}$ in that the influence of non-native species is reduced by applying the square root in the former.

\subsection{Three reference measures of wetland condition}

2.4.1 Impervious Surface Area. Impervious surface area (ISA) values were generated for each site as a landscape-level reference measure of wetland stress. Using ESRI ArcMap® 9.3 GIS software, 305-m surrounding-area polygons were generated for each site using the "buffer" command and selecting "outside only". Resulting surrounding-area polygons were used to clip recent high-resolution impervious surface raster data (RIGIS Impervious Surfaces, available: http://www.rigis.org), from which we calculated the proportion of impervious cover surrounding each site.

2.4.2 Rhode Island Rapid Assessment Method. Rhode Island Rapid Assessment Method (RIRAM) was conducted according to Kutcher (2010). RIRAM is an evidence-based rapid assessment method that was developed to produce a relative index of freshwater wetland condition based on rating and summing the estimated intensity and impact of multiple human disturbances (Table S1), which closely follows EPA wetland monitoring and assessment guidelines (U.S. EPA, 2006). RIRAM scoring is based on the assumption that that the impacts of diverse human disturbances additively contribute to the degradation of general wetland condition (Fennessy et al., 2004; U.S. EPA, 2006); thus, a perfect RIRAM score of 100 indicates no observed evidence of anthropogenic disturbance or degradation. RIRAM meets EPA criteria for establishing a "reference gradient" of wetland condition across sites (Faber-Langendoen et al., 2009; U.S. EPA, 2006), as was applied in this study.

2.4.3 Odonata Index of Wetland Integrity. We used the Odonata Index of Wetland Integrity (OIWI) as an independent bioindicator of wetland disturbance (Kutcher and Bried, 2014). OIWI uses the aggregate conservatism of adult (winged) dragonflies and damselflies (Insecta: Odonata) to indicate relative ecological condition. Odonate CC were generated empirically by relating odonate survey data to landscape features reflecting human disturbance (Kutcher and Bried, 2014). For this current study, we refined odonate CC using additional survey data. The OIWI value for each of our 20 sites was calculated as the mean CC of odonate species surveyed.

242

\subsection{Relating FQA indices to reference measures}

Statistical analyses were conducted using WinSTAT® statistical software (2006, R. Fitch Software). Rank-based and non-parametric methods were used to compensate for the ordinal nature of the RIRAM data and for the skews and gaps inherent in the samples. Correlations between FQA variants and OIWI, RIRAM, and ISA values were tested using Spearman rank correlation $\left(r_{s}\right)$. Additionally, box-and-whisker analysis was used to evaluate FQA capacity to discriminate among disturbance classes, following Barbour et al. (1996). Specifically, sites were classified using quartiles of the RIRAM and ISA index values as: (1) least-disturbed (below 25th percentile), (2) intermediately-disturbed $\left(25^{\text {th }}-75^{\text {th }}\right.$ percentile), and (3) most-disturbed (above 75 th percentile). For each FQA variant, the degree of interquartile range separation or overlap was used to evaluate the capacity for the variant to discriminate among the disturbance classes (Barbour et al., 1996; Veselka et al., 2010). 
The effects of reduced sampling effort on the performance of FQA was tested by restatistical analyses for comparison against full-effort results. We assessed the effect of reducing effort in three ways: reducing the number of transects sampled, reducing the number of plants used per transect, and reducing both. Specifically, FQA indices calculated using vegetation data from a single (first) transect were compared with values using all three transects. Next, FQA indices calculated using only species with $\geq 10 \%$ cover (ranks 2 and 3) were compared to indices calculated with species from all cover classes. Finally, FQA indices calculated using only species with $\geq 10 \%$ cover surveyed in the first transect were compared with indices using all species in all transects.

\section{Results}

\subsection{FQA vegetation data}

The FQA vegetation surveys identified 271 vascular plant species, of which 27 (10\%) were classified as non-native and 10 (3.7\%) were classified as natives endangered in Rhode Island (RI Natural Heritage Program). Red maple (Acer rubrum) was the most commonly-identified species (19 sites), followed by highbush blueberry (Vaccinium corymbosum) (17 sites), although emergent forbs were most common overall (96 species in 293 occurrences), followed by shrubs (48 species in 240 occurrences) and graminoids (54 species in 179 occurrences). The number of species identified per site ranged from 19 to 96 (mean $\pm S D=50 \pm 21$ ), of which 0 to $28 \%$ were non-native. $F Q A I$ values ranged from 15.4 to 41.3 (28.5 \pm 6.36$), F Q A I_{s}$ values ranged from 13.7 to 43.4 (27.5 \pm 6.74$), F Q A I^{\prime}$ values ranged from 30.7 to 51.0 (41.6 \pm 6.22$)$, Mean $C C_{n}$ values ranged from 3.53 to 5.15 (4.29 \pm 0.48 ), Mean $C C_{s}$ values ranged from 2.56 to 5.04 (4.02 \pm 0.76 ), Weighted Mean $C C_{s}$ values ranged from 1.78 to 5.19 (3.96 \pm 0.96$)$, and \% Native values ranged from 72.2 to $100(93.1 \pm 8.85)$ (Table S2).

\subsection{Reference measure data}

ISA values ranged from 0.00 to $62.4 \%(11.5 \pm 17.1 \%)$, RIRAM values ranged from 44.2 to 100 (79.9 \pm 18.2$)$, and OIWI values ranged from 4.68 to 7.29 (5.92 \pm 0.80$)$ (Table S2). ISA was strongly correlated with RIRAM (Spearman rank, $\left.r_{s}=-0.92, P<0.01\right)$ and OIWI $\left(r_{\mathrm{s}}=-0.87, P<\right.$ $0.01)$, and RIRAM was strongly correlated with OIWI $\left(r_{s}=0.80, P<0.01\right)$. According to RIRAM data, the most commonly-observed stressors within sites were dams and roads, whereas the most common stressors from the surrounding landscape were raised roads, footpaths, and residential development. Twelve of the 20 sites were impounded by dams or roads and 12 were partly filled to upland grade, primarily from public roads and development filling. Invasive species cover ranged from none noted at nine sites to high (51-75\% cover) at two sites, with nonnative common reed (Phragmites australis), being the most-commonly detected invasive species.

\subsection{FQA variant performance}

Metric scores for four FQA index variants and for the proportion of native species ( $\%$ Native) were strongly correlated with all of our reference measures (Table 2); none of these incorporated proxies of species richness. The remaining two FQA indices tested, both of which incorporate information of species richness, were not correlated with any reference measures. Nor were two simple proxies for species richness (number of native species identified and total 
species identified), except that the number of total (including non-native) species identified significantly decreased with increasing RIRAM condition scores. Both proxies of species richness, and the two floristic variants incorporating those proxies, were strongly influenced by hydrogeomorphic class and were more likely to vary with site area, whereas hydrogeomorphology and site area had no effect on the four FQA indices that ignored richness (Table 3).

Table 2. Spearman rank correlation coefficients and probability values comparing various floristic measures against reference measures of freshwater wetland condition among 20 wetland sites.

\begin{tabular}{|c|c|c|c|c|c|c|}
\hline \multirow[t]{2}{*}{ Floristic Index } & \multicolumn{2}{|c|}{ OIWI } & \multicolumn{2}{|c|}{ RIRAM } & \multicolumn{2}{|c|}{$I S A$} \\
\hline & $r_{s}$ & $P$ & $r_{s}$ & $P$ & $r_{s}$ & $P$ \\
\hline$F Q A I$ & 0.24 & 0.31 & -0.08 & 0.73 & -0.09 & 0.69 \\
\hline$F Q A I_{s}$ & 0.39 & 0.09 & 0.11 & 0.64 & -0.27 & 0.25 \\
\hline Mean $C C_{n}$ & 0.75 & $<0.01$ & 0.70 & $<0.01$ & -0.70 & $<0.01$ \\
\hline Mean $C C_{s}$ & 0.82 & $<0.01$ & 0.81 & $<0.01$ & -0.84 & $<0.01$ \\
\hline Weighted Mean $C C_{s}$ & 0.82 & $<0.01$ & 0.85 & $<0.01$ & -0.86 & $<0.01$ \\
\hline$F Q A I^{\prime}$ & 0.82 & $<0.01$ & 0.78 & $<0.01$ & -0.80 & $<0.01$ \\
\hline$\%$ Native & 0.81 & $<0.01$ & 0.89 & $<0.01$ & -0.89 & $<0.01$ \\
\hline Native Species Richness & -0.13 & 0.58 & -0.40 & 0.08 & 0.27 & 0.25 \\
\hline Total Species Richness & -0.29 & 0.21 & -0.54 & 0.01 & 0.44 & 0.05 \\
\hline
\end{tabular}

Table 3. Kruskal-Wallace $H$-values (non-parametric analog to ANOVA) and Spearman rank correlation coefficients $\left(r_{s}\right)$ comparing measures of freshwater wetland condition against hydrogeomorphic class and site size $(n=20)$, among 20 freshwater wetland sites

\begin{tabular}{lrrrr}
\hline Floristic Index & \multicolumn{2}{c}{ Hydrogeomrophic Class } & \multicolumn{2}{c}{ Site Area } \\
\cline { 2 - 3 } & $H$ & $P$ & $r_{s}$ & $P$ \\
\hline Floristic Index Incorporating Richness & & & & \\
Native Species & 10.25 & 0.01 & 0.44 & 0.06 \\
Total Species & 7.84 & 0.02 & 0.48 & 0.03 \\
FQAI & 11.11 & $<0.01$ & 0.43 & 0.06 \\
FQAI & 10.06 & 0.01 & 0.31 & 0.18 \\
Floristic Index Discounting Richness & & & & \\
Mean CC & 1.05 & 0.59 & 0.18 & 0.45 \\
Mean CC & 1.70 & 0.43 & 0.03 & 0.88 \\
Weighted Mean CC & 0.84 & 0.65 & -0.07 & 0.77 \\
FQAI' & 1.65 & 0.44 & 0.06 & 0.79 \\
\% Native & 3.74 & 0.15 & -0.28 & 0.23 \\
Reference Measure & & & & \\
OIWI & 2.28 & 0.32 & -0.07 & 0.39 \\
RIRAM & 2.91 & 0.23 & -0.30 & 0.20 \\
ISA & 1.93 & 0.38 & 0.25 & 0.29 \\
\hline
\end{tabular}

Mean $C C_{s}$, Weighted Mean $C C_{s}$, and \% Native index values were most strongly correlated with the three reference measures ( $r_{s}$ always $>0.80$, Table 2$)$, and were thus considered best-fit floristic indices in further analyses. The variant $F Q A I^{\prime}$ was not included as a best-fit index or discussed further in detail because it is functionally similar to the more- 
straightforward Mean $C C_{s}$ (Table 1). The best-fit indices were significantly correlated with several of the component metrics of the RIRAM index, suggesting that a wide range of anthropogenic factors contributed to floristic variability (Table 4). However, none of the best-fit indices was strongly correlated with RIRAM metrics rating hydrologic modification, including impoundment, draining or diversion of water, and apparent hydrologic integrity, even though $60 \%$ of the sites were at least partly impounded.

Table 4. Spearman rank correlation coefficients comparing FQA indicators with RIRAM metrics and submetrics among 20 wetland sites. Parenthetic values are not significant using a Bonferroni-adjusted critical $P$ value of 0.0036 .

\begin{tabular}{lcccc}
\hline RIRAM Metric & Mean CC & Weighted Mean $C C_{s}$ & \%Native & $F Q A I$ \\
\hline RIRAM Stress Metric & & & & \\
Buffer Integrity & 0.77 & 0.76 & 0.85 & $(0.31)$ \\
Surrounding Land Use Integrity & 0.85 & 0.84 & 0.89 & $(0.13)$ \\
Impoundment & $(-0.09)$ & $(-0.16)$ & $(-0.18)$ & $(0.43)$ \\
Draining or Diversion of Water & $(0.50)$ & $(0.59)$ & $(0.49)$ & $(0.07)$ \\
Fluvial Inputs & -0.74 & -0.77 & -0.84 & $(-0.15)$ \\
Filling and Dumping & -0.76 & -0.83 & -0.62 & $(0.00)$ \\
Substrate Disturbance & -0.69 & -0.73 & $(-0.62)$ & $(0.01)$ \\
Vegetation Removal & $(-0.37)$ & $(-0.46)$ & $(-0.38)$ & $(-0.12)$ \\
Invasive Species Cover & -0.74 & -0.73 & -0.91 & $(0.00)$ \\
RIRAM Observed State Submetric & & & & \\
Hydrologic Integrity & $(0.50)$ & $(0.57)$ & $(0.43)$ & $(-0.27)$ \\
Water and Soil Quality & 0.80 & 0.82 & 0.84 & $(0.17)$ \\
Vegetation / Microhabitat Structure & 0.89 & 0.87 & 0.89 & $(0.23)$ \\
Vegetation Composition & 0.72 & 0.71 & 0.90 & $(0.08)$ \\
Habitat Connectivity & 0.69 & 0.72 & 0.83 & $(-0.15)$ \\
\hline
\end{tabular}

Distributions of Mean $C C_{s}$ and Weighted Mean $C C_{s}$ values were completely nonoverlapping between least-disturbed and most-disturbed reference categories identified by RIRAM and ISA (Fig. 1). In contrast, the distributions of FQAI values between least-disturbed and most-disturbed categories overlapped nearly completely according to both reference measures. The FQAI distribution showed a tendency toward higher values with intermediate disturbance according to RIRAM designations (Kruskal-Wallace, $H=5.1, P=0.08$ ). 

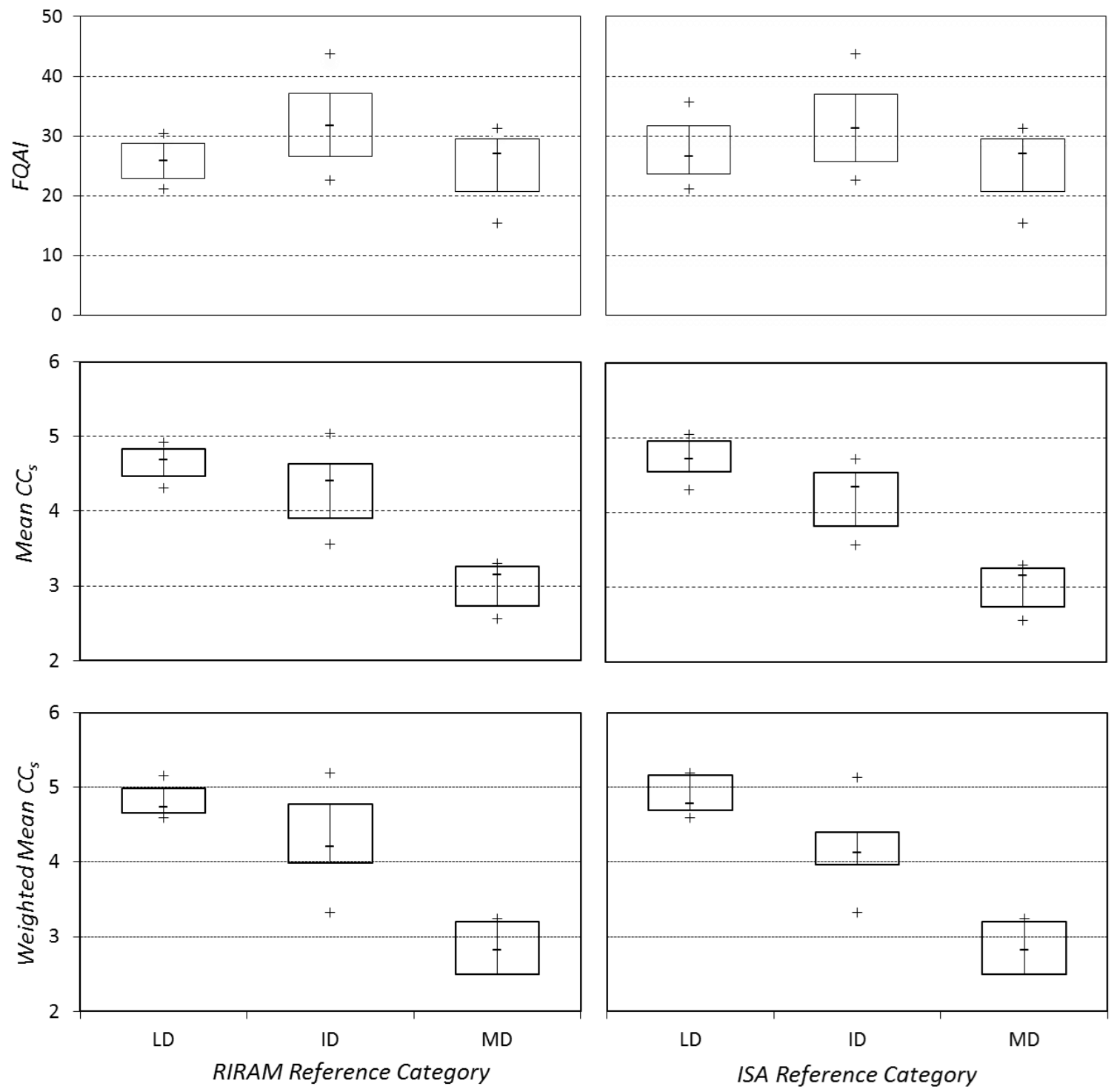

Fig. 1. Box plots depicting the distributions of FQA index values among RIRAM and ISA-based reference designations of freshwater wetland condition for 20 wetlands; boxes represent interquartile ranges, crosses represent minimum and maximum values, and dashes represent median values; $\mathrm{LD}=$ least disturbed, $\mathrm{ID}=$ intermediately disturbed, and $\mathrm{MD}=$ most disturbed.

\subsection{Reduced sampling effort}

Single-transect vegetation sampling of all cover classes (ranks 1-3) produced 15 to 71 vascular plant species per site with a mean of $39 \pm 17$; three-transect sampling of only rank 2 and 3 cover classes ( $\geq 10 \%$ total cover) produced 3 to 10 species per site with a mean of $6.1 \pm 2.1$; and single-transect sampling of only rank 2 and 3 cover classes produced 3 to 12 species per site with a mean of $6.9 \pm 2.4$. The strength of correlations between the best-fit floristic indices and the reference measures declined incrementally as sampling effort was reduced; this decline was most pronounced for \% Native with a reduction in cover classes sampled (Table 5). 
Table 5. Spearman rank correlation coefficients comparing full and reduced-effort floristic measures against existing measures of freshwater wetland condition among 20 reference wetland sites. Parenthetic values are not significant using a $P$ value of 0.05 .

\begin{tabular}{lccc}
\hline Floristic Index & OIWI & RIRAM & ISA \\
\hline Mean $C C_{s}$ & & & \\
Full Sampling & 0.82 & 0.81 & -0.84 \\
Single Transect & 0.82 & 0.79 & -0.82 \\
$\geq 10 \%$ Cover & 0.74 & 0.81 & -0.79 \\
Single Transect $\geq 10 \%$ Cover & 0.77 & 0.74 & -0.78 \\
Weighted Mean $C C_{s}$ & & & \\
Full Sampling & 0.82 & 0.85 & -0.86 \\
Single Transect & 0.82 & 0.83 & -0.84 \\
$\geq 10 \%$ Cover & 0.79 & 0.85 & -0.82 \\
Single Transect $\geq 10 \%$ Cover & 0.80 & 0.77 & -0.80 \\
$\%$ Native & & & \\
Full Sampling & 0.81 & 0.89 & -0.89 \\
Single Transect & 0.82 & 0.86 & -0.86 \\
$\geq 10 \%$ Cover & 0.73 & 0.70 & -0.71 \\
Single Transect $\geq 10 \%$ Cover & 0.73 & 0.67 & -0.70 \\
FQAI & & & \\
Full Sampling & $(0.24)$ & $(-0.08)$ & $(-0.09)$ \\
Single Transect & $(0.20)$ & $(-0.05)$ & $(-0.08)$ \\
$\geq 10 \%$ Cover & $(0.26)$ & $(0.36)$ & $(-0.24)$ \\
Single Transect $\geq 10 \%$ Cover & $(0.21)$ & $(0.09)$ & $(-0.16)$ \\
\hline
\end{tabular}

\section{Discussion}

\subsection{Empirical evaluation suggests some FQA variants are good bioindicators}

We evaluated FQA variants against reference measures representing three conceptual levels of assessment as recommended by U.S. EPA (2006): landscape (level 1), rapid (level 2), and intensive (level 3) methods. Each reference measure was independently conceptualized and developed based on ecological theory and not on improving its correlation with any other measure. It is assumed that these reference measures, representing indirect stress (ISA), direct and cumulative disturbance (RIRAM), and biological response (OIWI), are together reflecting a broad signal of disturbance, even as there is evidence of functional overlap. With this approach, we were able to evaluate broad aspects of FQA responsiveness and utility while increasing insight and confidence in our findings. The original FQAI did not effectively indicate wetland condition, whereas FQA variants excluding species richness were strongly correlated with all three reference measures of wetland condition and were able to clearly discriminate among disturbance classes, suggesting good indicator performance. Those richness-free variants incorporating non-native species (Mean $C C_{s}$, Weighted Mean $C C_{s}$, and $F Q A I^{\prime}$ ) outperformed the variant based strictly on native species (Mean $C C_{n}$ ), and incorporating species cover (Weighted Mean $C C_{s}$ ) did not substantially improve empirical performance further. Interestingly, the percentage of native species alone (\% Native) was also strongly correlated with our reference measures in full-effort sampling, suggesting a strong relationship between wetland disturbance and invasibility. 


\subsection{Support for floristic conservatism as an indicator of wetland integrity}

Strong correlation of aggregate floristic conservatism (Mean $C C_{n}$ and Mean $C C_{s}$ ) with the proportion of surrounding impervious surface (ISA) and our additive multi-metric assessment measure (RIRAM), supports the assumption that floristic conservatism can integrate and reflect cumulative impacts of multiple agents of disturbance (DeBerry et al., 2015; Faber-Langendoen, 2009; Mack and Kentula, 2010; U.S. EPA, 2002), a necessary trait for the broad assessment of ecological integrity (Barbour et al., 1996; Karr and Chu, 1999). Correlation with odonate conservatism (OIWI) supports predictable responsiveness of disturbance tolerance across taxa and the broader potential utility of conservatism. Floristic conservatism can be viewed as being underpinned by the C-S-R (Competitor, $\underline{\text { Stress-tolerant, }}$ Ruderal) life history theory (Grimes, 1974, 1977), wherein increasing disturbance favors survival of R (disturbance-facilitated) species (represented by low $\mathrm{CC}$ ) over conservative (disturbance-intolerant) $\mathrm{C}$ and $\mathrm{S}$ species, and thus the relative prevalence of $\mathrm{R}$ versus $\mathrm{C}-\mathrm{S}$ species reflects the degree of effective disturbance. This straightforward concept makes aggregate floristic conservatism a readily understood and interpreted metric, increasing its utility for managers. Additionally, it is easily measured, nondestructive, and measures a habitat characteristic closely tied to management concerns (Cairns et al., 1993; Dale and Bayler, 2001; Karr, 2006).

\subsection{Lack of support for species richness as a component of FQA}

Our results suggest that species richness impedes the ability of FQA indices to reflect changes in wetland condition due to human disturbances. We found that native species richness $(N)$ was not correlated with any measure of wetland condition (OIWI) or stress (RIRAM, ISA), and our work is consistent with other studies that have found that variants excluding species richness more reliably vary with wetland condition (Bried et al., 2013; Cohen et al., 2004; Matthews et al., 2009; Miller and Wardrop, 2006; Vaselka et al., 2010). We also found that richness-weighted FQA variants varied with hydrogeomorphic class, suggesting that species richness is innately variable across wetland types, independent of disturbance (Bried et al., 2013; Bourdaghs, 2012), which would confound comparison of condition across wetland types. In contrast, the non-richness-weighted FQA variants did not vary with wetland type and correlated strongly with our reference measures across wetland hydrogeomorphic and vegetation community types, suggesting greater utility and reduced classification burdens for managers.

Alongside the lack of empirical support for including species richness, there are conceptual grounds for care when including species richness in bioindicators. The widespread use of species richness in biological assessment is often motivated by its use as a proxy for community diversity in a broader sense, which is in turn considered to reflect high community productivity, resilience, and functionality (Knops et al., 1999; Myers et al., 2000; Rosset et al., 2013; Tilman et al., 1996). Under this assumption, reduced species richness is expected in areas disturbed by human activity and high richness should indicate undisturbed habitat. Potentially undermining this assumption is the fact that species richness is not always a reliable proxy for other components of diversity (Keough and Quinn, 1991; Grimes, 1997; Waide et al., 1999). In addition, ecological theory predicts varying and non-linear relationships between richness and disturbance (Connell, 1978; Huston, 1979; Miller et al., 2011; Violle et al., 2010), and our findings support other empirical studies substantiating this expectation (Mackey and Currie, 2001). When there is a monotonic decline in species richness with increasing disturbance, this pattern may only hold for small, uniform habitat patches, and can be offset by patchy or 
incomplete incursions that increase richness when sites encompass multiple habitat types (Catford et al., 2012; Didham et al., 2005; Silliman and Bertness, 2004).

Another practical drawback of using species richness in bioindicators, recognized by early proponents (Fausch et al., 1990), is its dependence on site area and sampling effort (Connor and McCoy 1979; Gotelli and Colwell, 2001; Rooney and Rogers, 2002). In theory, FQA requires a complete floristic inventory, but this is not often practical, particularly for large or complex areas. Bourdaghs et al. (2006) addressed site area dependence by aggregating FQAI scores from several equal-sized subunits within a site. Our belt-transect sampling method somewhat normalized effort in relation to site area, yet nearly all floristic measures incorporating species richness varied with site area. Fully standardizing sampling effort could potentially lessen, but not eliminate, these effects (Washington, 1984).

\subsection{Support for non-native species as components of FQA}

Of the FQA variants that did not incorporate species richness, those including non-native species (Mean $C C_{s}$, Weighted Mean $C C_{s}$, and $F Q A I^{\prime}$ ) were most-strongly associated with our reference measures. In fact, the simplest measure of non-native-species prevalence (\% Native), was strongly correlated with our reference measures and with multiple RIRAM component metrics. Some other studies also report improved performance when comparing FQA indicators with and without non-native species, e.g. Mean $C C_{s}$ vs. Mean $C C_{n}$ (Cohen et al., 2004) and nonnative species richness vs. FQAI (Ervin et al., 2006), whereas others report no performance differences (Bourdaghs et al., 2006; Miller and Wardrop, 2006). We cannot explain these among-study differences in the empirical influence of non-native species on FQA indicators, but speculate that it may reflect the overall prevalence of non-natives.

FQA variants that include non-native species generally assign all non-native species a CC of 0 , which assumes all are equally and highly tolerant of human disturbances. Although there is support for the hypothesis that non-natives tend to differ in several performance-related traits from native species (van Kleunen et al., 2010), their characteristics vary considerably (Sakai, 2001) so it is perhaps more realistic to assume their CC values are low, but variable, rather than all zero (DeBerry et al., 2015). There is, perhaps, stronger evidence that native communities are more invasible after human disturbance, supporting the assumption that high representation of non-natives is a symptom (rather than a cause) of habitat disturbance (Didham et al., 2005; Vitousek et al., 1996). Additionally, changes in plant species composition and structure associated with invasive species presence and abundance are, by definition, direct changes in ecological condition, which FQA typically seeks to measure. There is thus both empirical and conceptual backing for the inclusion of non-native species in FQA, and the straightforward aggregate conservatism of all species $\left(\right.$ Mean $\left.C C_{s}\right)$ is an understandable and reliable indicator for practitioners seeking to evaluate general wetland condition.

\subsection{Conceptual support for incorporating abundance in FQA}

Weighted Mean $C C_{s}$ performed similarly to Mean $C C_{s}$ in this study, but there are important ecological and practical implications of incorporating abundance in FQA. Weighted Mean $C C_{s}$ better reflects wetland condition in cases where a single or few ruderal species dominate groundcover and remnant conservative vegetation remains (Bourdaghs, 2012), which is common with incursions of nuisance and invasive species, such as Phragmites australis. Weighting Mean $C C_{s}$ by relative cover captures the structural and functional implications of groundcover domination by ruderal species that Mean $C C_{s}$ alone cannot, and therefore provides a 
more relevant and defensible indication of wetland condition at the site scale, which is essential for comparing individual assessment outcomes. Among wetlands with more even species distributions, Mean $C C_{s}$ and Weighted Mean $C C_{s}$ function nearly equally. Prior studies with similar empirical findings have suggested that incorporating abundance classes is not worth the extra sampling effort (Bourdaghs et al., 2006; Cohen et al., 2004), but later, more-intensive work emphasizes the importance of abundance weighting in FQA from both empirical and conceptual standpoints (Bourdaghs, 2012). Unlike the more-rigorous methods used in the earlier studies, the sampling methods developed for our study, which focus on species identification and the estimation of broad cover classes, capture the functional consequences of cover domination with little extra effort over identity sampling alone $(\sim 3 \mathrm{~min}$. per transect $\times 3$ transects $=\sim 9 \mathrm{~min}$. per site for full-effort sampling). We argue that, using our simplified cover-estimation approach, the increased functionality of Weighted Mean $C C_{s}$ at the site scale is well worth the small added increase in effort for evaluating individual wetlands.

\subsection{Sampling effort and performance}

Three practical considerations for FQA practitioners are index performance (reliability), available botanical expertise, and the amount of time a method takes to conduct. Our full-effort sampling time was practical, usually completed in less than three hours of field work and an hour or two of laboratory support. Botanical expertise may therefore pose the most likely limitation to practitioners (Chamberlain and Brooks, 2016). Our reduced cover-class sampling reduced species identification requirements from a mean of 50 for full-effort sampling to a mean of 6 or 7 and as few as 3 , greatly alleviating expertise and time limitations without strongly degrading index performance. These findings support recommendations that a limited number of commonly-occurring indicator species can be used to reduce botanical expertise requirements without substantially degrading index reliability (Bourdaghs, 2012). Additionally, our findings indicate that Mean $C C_{s}$ and Weighted Mean $C C_{s}$ became stable using data from a single transect, suggesting that exhaustive sampling may be unnecessary for these richness-free FQA variants to produce a reliable score (Bourdaghs et al., 2006).

\subsection{FQA indicators may not reflect hydrological modification to wetlands}

Despite good overall performance, FQA may not be a reliable indicator of hydrologic modifications. Weak correlations between FQA measures and RIRAM metrics rating hydrologic modification suggest that hydrologic modification does not strongly affect aggregate conservatism or proportional nativeness of plant species, even though it is known to largely control species composition (Mitsch and Gosselink, 2000). Consonantly, Ervin et al. (2006) found wetland indicator status (fidelity to wetland hydrology) to be a relatively ineffective indicator of wetland integrity. Our findings may reflect a resilient adaptability of wetlands to hydrologic change and the potential for high quality wetlands to persist in artificial water regimes.

\subsection{Study sample implications}

We are confident that our study sample represented a broad range of wetland conditions, as RIRAM scores ranged from 100, indicating no perceived evidence of disturbance or degradation, to 44.2 , which indicates moderate to high-intensity disturbance and degradation across multiple metrics (Tables S1 and S2). Our approach of using three largely independent reference measures reduced reference measure bias, but it did not alleviate the limitations of our 
study sample, which included mostly open-canopy vegetated wetlands. Recent work using this same approach has indicated that FQA is similarly effective in forested wetlands in Rhode Island (M. Peach-Lang, unpublished data), a finding shared by Bell et al. (2017) in Northern New England forested wetlands. Other studies recommend interpreting FQA scores differently across various wetland types (Bourdaghs, 2012; DeBerry et al., 2015). We found no evidence that hydrogeomorphic type confounded non-richness FQA across our sites, but our study sample was too small to make determinations on whether or to what extent differential interpretation of FQA may be necessary for specific wetland types in our region. We recommend rigorous study using multiple independent reference measures for developing FQA protocols for specific regions.

\subsection{Conclusion}

We demonstrate that a straightforward bioindicator can predictably integrate and reflect the complex signal of cumulative wetland disturbance. We tested FQA against three independently-derived reference measures, which provided a broad signal of wetland integrity and increased our confidence that FQA variants were responding to the signal of disturbance over the biases of our reference measures. Interpreting our empirical findings in the context of established ecological theory provides insight into the mechanisms driving the FQA variants. Our analysis discredits the assumption that species richness supports FQA functionality, suggesting that richness will more often confound FQA function without providing predictably meaningful information about wetland condition. Our findings support the assumptions that (1) aggregate conservatism will reliably decline with increasing human disturbance; (2) non-native species support conservatism by directly reflecting wetland ecological integrity; and (3) the relative abundance of species can add important site-level functional information that species presence alone cannot provide. Our analysis suggests that FQA variants incorporating non-native species and discounting species richness respond meaningfully and predictably across a gradient of ecological conditions, are resistant to the confounding influences of site size, sampling effort, and hydrogeomorphology, and are easily interpreted and understood. Incorporating relative abundance (Weighted Mean $C_{s}$ ) using the coarse cover classes recommended in this study improves relevance at the site level with little extra sampling effort. Accordingly, the straightforward principles and methods of FQA can provide practitioners with a set of practical, reliable, and informative tools for assessing freshwater wetland integrity.

\section{Acknowledgments}

We thank Carolyn Murphy, Keith Killingbeck, Rick McKinney, Evan Priesser, and Jason Bried for providing technical advice. David Gregg, Susan Kiernan, and Carolyn Murphy administered this work, and Stacey Liecht Young, Grace Lentini, and Rick Enser assisted with vegetation sampling and data summary. Kerry Strout and Jason Bried coordinated the regional assignment of floristic coefficients of conservatism, and Rick Enser assigned the coefficients of conservatism applied in this study. Rhode Island Natural History Survey is generously housed by the University of Rhode Island, College of the Environment and Life Sciences. This project was funded by the Rhode Island Department of Environmental Management, Office of Water Resources, through a Wetlands Program Development Grant awarded by the United States 


\section{Literature Cited}

Barbour, M.T., Gerritsen, J., Griffith, G.E., Frydenborg, R., McCarron, E., White, J.S., Bastian, M.L., 1996. A framework for biological criteria for Florida streams using benthic macroinvertebrates. J. N. Am. Benthol. Soc. 15, 185-211.

Bell, J.L., Boyer, J.N., Crystall, S.J., Nichols, W.F., Pruyn, M., 2017. Floristic quality as an indicator of human disturbance in forested wetlands of northern New England. Ecol. Indic., 83, 227-231.

Birk, S., Bonne, W., Borja, A., Brucet, S., Courrat, A., Poikane, S., Solimini, A., Van de Bund, W., Zampoukas, N., Hering, D., 2012. Three hundred ways to assess Europe's surface waters: an almost complete overview of biological methods to implement the Water Framework Directive. Ecol. Indic. 18, 31-41.

Bourdaghs, M., 2012. Development of a rapid floristic quality assessment. wq-bwm2-02a. Minnesota Pollution Control Agency, St. Paul.

Bourdaghs, M., Johnston, C. A., Regal, R.R., 2006. Properties and performance of the floristic quality index in Great Lakes coastal wetlands. Wetlands 26, 718-735.

Bried, J.T., Jog, S.K., Matthews, J.W., 2013. Floristic quality assessment signals human disturbance over natural variability in a wetland system. Ecol. Indic. 34, 260-267.

Bried, J.T., Strout, K.L., Portante, T., 2012. Coefficients of conservatism for the vascular flora of New York and New England: inter-state comparisons and expert opinion bias. Northeast. Nat. 19, 101-114.

Brinson, M.M. 1993. A hydrogeomorphic classification for wetlands. U.S. Army Corps of Engineers Technical Report WRP-DE-4. Waterways Experiment Station, Vicksburg, MS, USA.

Cairns Jr., J., McCormick, P.V., Niederlehner, B.R., 1993. A proposed framework for developing indicators of ecosystem health. Hydrobiologia 263, 1-44.

Catford, J.A., Daehler, C.C., Murphy, H.T., Sheppard, A.W., Hardesty, B.D., Westcott, D.A., Rejmánek, M., Bellingham, P.J., Pergl, J., Horvitz, C.C. and Hulme, P.E., 2012. The intermediate disturbance hypothesis and plant invasions: Implications for species richness and management. Perspect. Plant Ecol. 14, 231-241.

Chamberlain, S.J., Brooks, R.P., 2016. Testing a rapid Floristic Quality Index on headwater wetlands in central Pennsylvania, USA. Ecol. Indic. 60, 1142-1149.

Cohen, M.J., Carstenn, S., Lane, C.R., 2004. Floristic quality indices for the assessment of depressional marsh condition in Florida. Ecol. Appl. 14, 784-794.

Ekberg, M.L.C., Raposa, K.B., Ferguson, W.S., Ruddock, K., Watson, E.B., 2017. Development and application of a method to identify salt marsh vulnerability to sea level rise. Estuar. Coast. 40, 694-710.

Connell, J.H. 1978. Diversity in tropical rain forests and coral reefs. Science 199, 1302-1310.

Connor, E.F., McCoy, E.D., 1979. The statistics and biology of the species-area relationship. Am. Nat. 113, 791-833.

Cowardin, L.M., Carter, V., Golet, F.C., LaRoe, E.T., 1979. Classification of wetlands and deepwater habitats of the United States. Office of Biological Services, Fish and Wildlife Service, U.S. Department of the Interior, Washington, DC.

Dale, V.H., Beyeler, S.C., 2001. Challenges in the development and use of ecological indicators. Ecol. Indic. 1, 3-10.

DeBerry, D.A., Chamberlain, S.J., Matthews, J.W., 2015. Trends in floristic quality assessment for wetland evaluation. Wetland Science and Practice 32, 12-22. 
Didham, R.K., Tylianakis, J.M., Hutchison, M.A., Ewers, R.M., Gemmell, N.J., 2005. Are invasive species the drivers of ecological change? Trends Ecol. Evol. 20, 470-474.

Ervin, G.N., Herman, B.D., Bried, J.T., Holly, D.C., 2006. Evaluating non-native species and wetland indicator status as components of wetland floristic assessment. Wetlands 26, 1114-1129.

Faber-Langendoen, D., Lyons, R., Comer, P., 2009. Developing options for establishing reference conditions for wetlands across the lower 48 states. A report to the U.S. Environmental Protection Agency. NatureServe, Arlington, VA.

Fausch, K.D., Lyons, J., Karr, J.R., Angermeier, P.L., 1990. Fish communities as indicators of environmental degradation. Am. Fish. S. S. 8, 123-144.

Fennessy, M.S., Jacobs, A.D., Kentula, M.E., 2004. An evaluation of rapid methods for assessing the ecological condition of wetlands. Wetlands 27, 543-560.

Freyman, W.A., Masters, L.A., Packard, S., 2016. The Universal Floristic Quality Assessment (FQA) Calculator: an online tool for ecological assessment and monitoring. Methods Ecol. Evol. 7, 380-383.

Gotelli, N.J., Colwell, R.K., 2001. Quantifying biodiversity: procedures and pitfalls in the measurement and comparison of species richness. Ecol. Lett. 4, 379-391.

Grime, J.P. 1974. Vegetation classification by reference to strategies. Nature 250, 26-31.

Grime, J.P. 1977. Evidence for the existence of three primary strategies in plants and its relevance to ecological and evolutionary theory. Am. Nat. 111, 1169-1194.

Grime, J.P. 1997. Biodiversity and Ecosystem Function: The Debate Deepens. Science 277, 1260-1261.

Huston, M. A. 1979. A general hypothesis of species diversity. Am. Nat. 113, 81-101.

Hilsenhoff, W.L. 1975. Aquatic insects of Wisconsin: generic keys and notes on biology, ecology and distribution. Wisconsin Department of Natural Resources Technical Bulletin No. 89. Madison, WI.

Invasive Plant Atlas of New England, 2011. https://www.eddmaps.org/ipane/ (accessed November 2011).

Karr, J.R. 1991. Biological integrity: a long-neglected aspect of water resource management. Ecol. Appl. 1, 66-84.

Karr, J.R. 2006. Seven foundations of biological monitoring and assessment. Biologia 20, 7-18.

Karr, J.R., Chu, E.W., 1999. Restoring Life in Running Waters; Better Biological Monitoring. Island Press, Washington, DC.

Keough, M., Quinn, G., 1991. Causality and the choice of measurements for detecting human impacts in marine environments. Mar. Freshwater Res. 42, 539-554.

Knops, J.M., Tilman, D., Haddad, N.M., Naeem, S., Mitchell, C.E., Haarstad, J., Ritchie, M.E., Howe, K.M., Reich, P.B., Siemann, E., Groth, J., 1999. Effects of plant species richness on invasion dynamics, disease outbreaks, insect abundances and diversity. Ecol. Lett. 2, 286-293.

Kutcher, T.E. 2011. Rhode Island rapid assessment method user's guide; RIRAM version 2.10. Rhode Island Department of Environmental Management, Office of Water Resources, Providence, RI.

Kutcher, T.E., Bried, J.T., 2014. Adult Odonata conservatism as an indicator of freshwater wetland condition. Ecol. Indic. 38, 31-39.

Lopez, R.D., Fennessey, M.S., 2002. Testing the floristic quality assessment index as an indicator of wetland condition. Ecol. Appl. 12, 487-497. 
Mackey, R.L., Currie, D.J., 2001. The diversity-disturbance relationship: is it generally strong and peaked? Ecology 82, 3479-3492.

Matthews, J.W., Spyreas, G., Long, C.M., 2015. A null model test of Floristic Quality Assessment: Are plant species' Coefficients of Conservatism valid? Ecol. Indic. 52, 1-7.

Matthews, J.W., Spyreas, G., Emdress, A.G., 2009. Trajectories of vegetation-based indicators used to assess wetland restoration progress. Ecol. Appl. 19, 2093-2107.

Myers, N., Mittermeier, R.A., Mittermeier, C.G., Da Fonseca, G.A., Kent, J., 2000. Biodiversity hotspots for conservation priorities. Nature, $403,853$.

Miller, A.D., Roxburgh, S.H., Shea, K., 2011. How frequency and intensity shape diversitydisturbance relationships. P. Natl. A. Sci. USA 108, 5643-5648.

Miller, S.J., Wardrop, D.H., 2006. Adapting the floristic quality assessment index to indicate anthropogenic disturbance in central Pennsylvania wetlands. Ecol. Indic. 6, 313-326.

Mirazadi, Z., Pilehvar, B., Vajari, K.A., 2017. Diversity indices or floristic quality index: Which one is more appropriate for comparison of forest integrity in different land uses? Biodivers. .Conserv. 26, 1087-1101.

Mitsch, W.J., Gosselink, J.G., 2000. Wetlands, Third Edition. John Wiley and Sons, New York.

Niemi, G. J., McDonald, M.E., 2004. Application of ecological indicators. Annu. Rev. Ecol. Evol. S. 89-111.

Rooney, T. P., Rogers, D.A., 2002. The Modified Floristic Quality Index. Nat. Area. J. 22, 340344.

Rosset, V., Simaika, J.P., Arthaud, F., Bornette, G., Vallod, D., Samways, M.J., Oertli, B., 2013. Comparative assessment of scoring methods to evaluate the conservation value of pond and small lake biodiversity. Aquat. Conserv. 23, 23-36.

Silliman, B.R., Bertness, M.D., 2004. Shoreline development drives invasion of Phragmites australis and the loss of plant diversity on New England salt marshes. Conserv. Biol. 18, 1424-1434.

Suir, G.M., Sasser, C.E., 2017. Floristic Quality Index of Restored Wetlands in Coastal Louisiana. ERDC/EL TR-17-15, U.S. Army Corps of Engineers, Vicksburg, LA.

Swink, F., Wilhelm, G., 1979. Plants of the Chicago Region; Revised and Expanded Edition with Keys. The Morton Arboretum, Lisle, IL.

Tilman, D., Wedin, D., Knops, J., 1996. Productivity and Sustainability Influenced by Biodiversity in Grassland Ecosystems. Nature 379, 718-720.

U.S. EPA, 2002. Methods for evaluating wetland condition: Developing metrics and indexes of biological integrity. EPA 822-R-02-016. Office of Water, U.S. Environmental Protection Agency, Washington, DC.

U.S. EPA, 2006. Application of elements of a state water monitoring and assessment program for wetlands. EPA 841-B-03-003. Wetlands Division, Office of Wetlands, Oceans and Watersheds, U.S. Environmental Protection Agency, Washington, DC.

Van Kleunen, M., Weber, E., Fischer, M., 2010. A meta-analysis of trait differences between invasive and non-invasive plant species. Ecol. Lett. 13, 235-245.

Veselka, W., Rentch, J.S., Grafton, W.N., Kordek, W.S., Anderson, J.T., 2010. Using two classification schemes to develop vegetation indices of biological integrity for wetlands in West Virginia, USA. Environ. Monit. Assess. 170, 555-569.

Violle, C., Pu, Z.C., Jiangm, L., 2010 Experimental demonstration of the importance of competition under disturbance. P. Natl. A. Sci. USA 107:12,925-12,929. 
699 Waide, R.B., Willig, M.R., Steiner, C.F., Mittelbach, G., Gough, L., Dodson, S.I., Juday, G.P., $700 \quad$ Parmenter, R., 1999. The relationship between productivity and species richness. Annu. $701 \quad$ Rev. Ecol. Syst. 30, 257-300.

702 Washington, H.G. 1984. Diversity, biotic and similarity indices. Water Res. 18, 653-694.

703

704 


\begin{tabular}{|c|c|}
\hline RIRAM Metric & Metric Scoring Criteria \\
\hline 1. Buffer Integrity & Estimates \% cultural cover class within 100 ( $(30.5 \mathrm{~m})$ of site \\
\hline 2. Surrounding Land Use Integrity & $\begin{array}{l}\text { Generates a weighted average of four land-use-intensity } \\
\text { categories by relative proportion within 500' }(152 \mathrm{~m}) \text { of site }\end{array}$ \\
\hline 3. Impoundment & $\begin{array}{l}\text { Estimates water regime change and proportion of site affected, } \\
\text { and identifies barriers to resource movement }\end{array}$ \\
\hline 4. Draining or Diversion of Water & $\begin{array}{l}\text { Estimates water regime change due to draining or diversion of } \\
\text { water, and proportion of the site affected }\end{array}$ \\
\hline 5. Fluvial Inputs & $\begin{array}{l}\text { Estimates impacts of four types of fluvial inputs including } \\
\text { nutrients, sediments and solids, toxins and salts, and flashiness }\end{array}$ \\
\hline 6. Filling and Dumping & $\begin{array}{l}\text { Estimates the intensity of fill and the proportion of the wetland } \\
\text { affected }\end{array}$ \\
\hline 7. Substrate Disturbance & $\begin{array}{l}\text { Estimates the intensity any substrate disturbances within the } \\
\text { wetland and the proportion of the wetland affected }\end{array}$ \\
\hline 8. Vegetation Removal & $\begin{array}{l}\text { Estimates the extent and the proportion of vegetation and detritus } \\
\text { removal from each of five vegetation strata }\end{array}$ \\
\hline 9. Invasive Species Cover & $\begin{array}{l}\text { Estimates the collective cover class of all identified invasive } \\
\text { plant species }\end{array}$ \\
\hline 10. Observed State of Wetland Characteristics & $\begin{array}{l}\text { Rates the apparent integrity of five wetland functional } \\
\text { characteristics, including hydrologic integrity, water and soil } \\
\text { quality, habitat structure, vegetation composition, and habitat } \\
\text { connectivity }\end{array}$ \\
\hline
\end{tabular}


709 Table S2. Values of floristic, Odonate, rapid, and landscape assessment indices of freshwater 710 wetland condition from 20 wetland sites; $M C C_{n}=$ Mean $C C_{n} ; M C C_{s}=$ Mean $C C_{s} ; W M C C_{s}=$ 711 Weighted Mean $C C_{s}$

\begin{tabular}{|c|c|c|c|c|c|c|c|c|c|c|c|c|}
\hline Site Code & $F Q A I$ & $F Q A I_{s}$ & $M C C_{n}$ & $M C C_{s}$ & $W M C C_{s}$ & $F Q A I^{\prime}$ & $N$ & $S$ & $\% N$ & OIWI & RIRAM & $I S A$ \\
\hline AUD-NEW-PND & 30.9 & 30.4 & 3.86 & 3.74 & 3.95 & 38.0 & 64 & 66 & 97.0 & 5.83 & 87.2 & 3.3 \\
\hline PRV-BLRD-PRK & 15.4 & 13.7 & 3.53 & 2.79 & 2.74 & 31.4 & 19 & 24 & 79.2 & 4.80 & 63.9 & 13 \\
\hline PRV-BOTH-PND & 30.4 & 30.4 & 4.69 & 4.69 & 4.59 & 46.9 & 42 & 42 & 100 & 6.82 & 93.7 & 0.3 \\
\hline PRV-BRCH-STA & 31.7 & 30.8 & 3.76 & 3.56 & 3.32 & 36.6 & 71 & 75 & 94.7 & 5.89 & 86.3 & 3.2 \\
\hline PRV-GLAC-PND & 24.8 & 23.3 & 4.45 & 4.06 & 4.20 & 43.1 & 31 & 33 & 93.9 & 6.24 & 82.0 & 6.3 \\
\hline PRV-JACK-SCPD & 32.3 & 32.3 & 4.43 & 4.43 & 4.06 & 44.3 & 53 & 53 & 100 & 5.95 & 84.9 & 1.6 \\
\hline PRV-LONS-MRSH & 28.5 & 26.2 & 3.81 & 3.25 & 2.86 & 35.4 & 56 & 65 & 86.2 & 4.92 & 57.6 & 19 \\
\hline PRV-MOSH-PND & 22.5 & 18.8 & 3.61 & 2.56 & 1.78 & 30.7 & 39 & 54 & 72.2 & 4.68 & 44.2 & 62 \\
\hline PRV-PYSZ-FEN & 28.3 & 27.9 & 4.85 & 4.71 & 5.13 & 47.8 & 34 & 35 & 97.1 & 6.34 & 88.8 & 3.1 \\
\hline PRV-SLTR-PRK0 & 31.3 & 28.9 & 3.85 & 3.30 & 2.77 & 35.6 & 66 & 77 & 85.7 & 5.30 & 50.4 & 31 \\
\hline PRV-WOON-STA3 & 29.0 & 26.3 & 3.87 & 3.24 & 3.25 & 35.6 & 56 & 66 & 84.8 & 4.96 & 54.9 & 38 \\
\hline PRV-WOON-STA4 & 25.6 & 22.5 & 3.95 & 3.06 & 3.19 & 34.7 & 41 & 53 & 77.4 & 4.73 & 55.5 & 35 \\
\hline SMA-ARC-BFFEN & 27.2 & 27.2 & 4.31 & 4.31 & 4.73 & 43.1 & 39 & 39 & 100 & 7.29 & 99.7 & 0.0 \\
\hline SMA-ARC-MOON & 38.6 & 37.9 & 4.71 & 4.56 & 4.32 & 46.4 & 62 & 64 & 96.9 & 5.94 & 86.3 & 8.3 \\
\hline SMA-ARC-RBPD & 43.7 & 43.4 & 4.46 & 4.41 & 4.43 & 44.4 & 95 & 96 & 99.0 & 6.77 & 87.7 & 0.8 \\
\hline SMA-BIG-CAP & 35.7 & 35.3 & 5.15 & 5.04 & 5.19 & 51.0 & 48 & 49 & 98.0 & 6.54 & 87.2 & 0.7 \\
\hline SMA-BUCK-PD & 24.5 & 24.5 & 4.63 & 4.63 & 4.82 & 46.3 & 27 & 27 & 100 & 5.85 & 99.7 & 0.7 \\
\hline SMA-CAR-FISH & 21.2 & 21.2 & 4.74 & 4.74 & 5.16 & 47.4 & 19 & 19 & 100 & 6.47 & 100 & 0.0 \\
\hline SMA-CAR-WLPD & 25.8 & 25.6 & 4.96 & 4.93 & 4.73 & 49.6 & 27 & 27 & 100 & 7.04 & 100 & 0.0 \\
\hline TNC-CRTR-WET1 & 22.7 & 22.7 & 4.29 & 4.29 & 4.03 & 42.9 & 28 & 28 & 100 & 6.15 & 87.8 & 3.6 \\
\hline
\end{tabular}

